\title{
A case of extradural spinal meningioma
}

\author{
J. F. HALLPIKE ${ }^{1}$ AND P. STANLEY \\ From the National Hospital for Nervous Diseases, Queen Square, London
}

Meningiomas are among the commonest primary extramedullary spinal neoplasms (Broager, 1953; Lombardi and Passerini, 1961) and are most frequently encountered in the dorsal region (Sloof, Kernohan, and MacCarty, 1964). They usually arise within the dura, sometimes extend beyond it, but are rarely extradural in toto (Rasmussen, Kernohan, and Adson, 1940). When, however, this does occur, spinal meningiomas share with other predominantly extradural neoplasms, notably neurofibromas, a tendency to extend through adjacent intervertebral foramina into the thorax (Heuer, 1929; Naffziger and Brown, 1933). According to Bull (1953) and Gautier-Smith (1967), bony radiological changes are rare with meningiomas but common with neurofibromas, thus providing a valuable criterion for their differential diagnosis. The case to be described -in which an extradural meningioma with a large intrathoracic extension, and having the radiological features usually associated with a neurofibroma, was successfully removed-is exceptional and affords an opportunity to discuss features of clinical and radiological interest.

\section{CASE REPORT}

An airframe fitter aged 33 was admitted to the National Hospital (N.H.A.: 34233) under the care of Dr. Denis Williams in January 1967. He had noticed pain in the mid-dorsal region for three and a half years which was aggravated by movement and coughing. Flexion and rotation of his head produced momentary tingling sensations in the back and legs. Six weeks before admission he developed increasing weakness of the legs, particularly the right, and a day before admission he became aware of disturbed sensation from the lower part of the chest downwards affecting both legs equally. Sphincter control remained unimpaired. There were no respiratory symptoms.

Examination showed no abnormality in the cranial nerves or arms. There was a moderately severe paraparesis involving the right leg more than the left. Tendon reflexes in the legs were symmetrically brisk; the plantar responses were extensor and. all abdominal reflexes absent. Pin appreciation was impaired below D6 on both sides.

'Present address: Department of Pathology, Guy's Hospital Medical School, London, S.E.1.
Vibration sense was absent at the toes but was present at both ankles. Other forms of sensation were intact. He had marked local tenderness over the spinous process of D6 and head movements reproduced the tingling he had noted previously. The rest of the examination was normal.

INVESTIGATIONS The urine was normal, haemoglobin $16.1 \mathrm{~g} / 100 \mathrm{ml}$., white cell count normal, and E.S.R. $4 \mathrm{~mm}$ in one hour. The W.R. was negative. Radiographs of the chest (Fig. 1) and dorsal spine (tracing diagram Fig. 2) showed complete absence of the lower half of the right pedicle of D6. The upper half of the pedicle was intact and the interpedicular distance was normal. The lower border of the right sixth rib was smoothly eroded just lateral to its neck; beneath this portion of the rib there was a rounded soft tissue mass of about $3 \mathrm{~cm}$ diameter. Positive contrast lumbar myelography carried out shortly

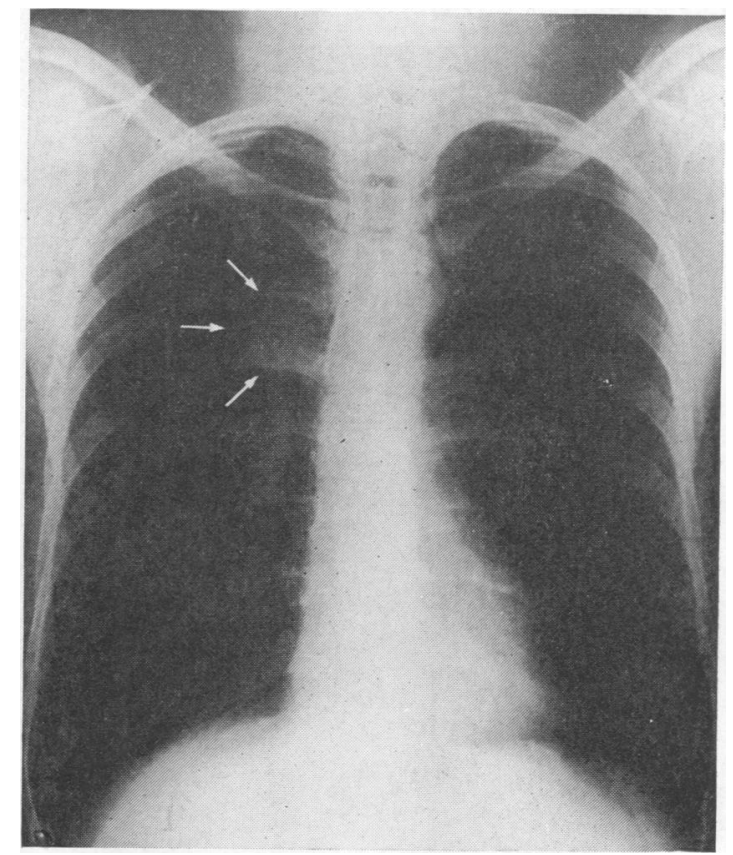

FIG. 1. Chest radiograph showing soft tissue mass (indicated by arrows) with erosion of lower border of right sixth rib posteriorly. 


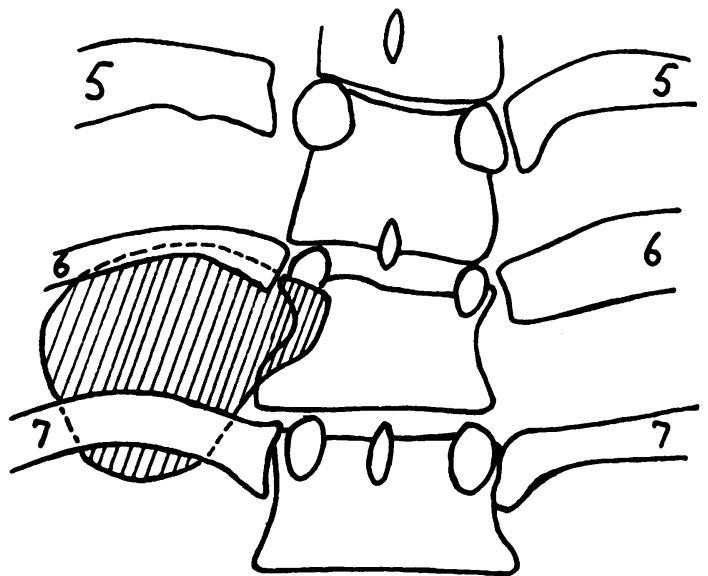

FIG. 2. Diagram traced from radiograph of dorsal spine showing tumour outline and details of bone erosion.

after admission demonstrated a complete obstruction to the flow of Myodil at D6 with displacement of the cord and theca to the left (Fig. 3). The protein content of the cerebrospinal fluid was $250 \mathrm{mg} / 100 \mathrm{ml}$. The radiological findings were pathognomonic of a dumb-bell mass and myelography showed it to be entirely extradural. These appearances combined with the high protein content of the cerebrospinal fluid led to a diagnosis of neurofibroma.

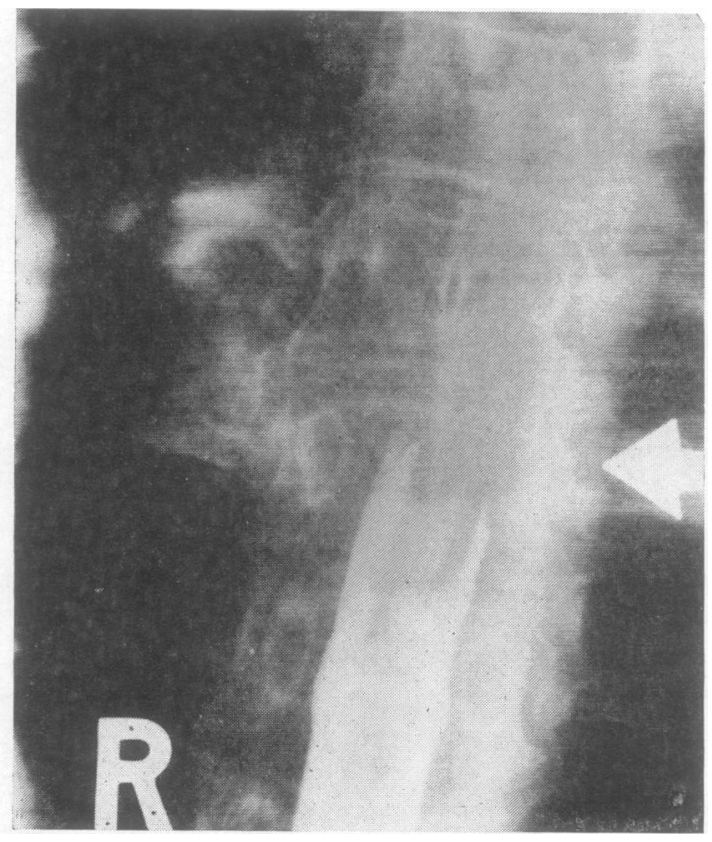

FIG. 3. Myelographic block at D.6 with displacement of cord and theca to the left.

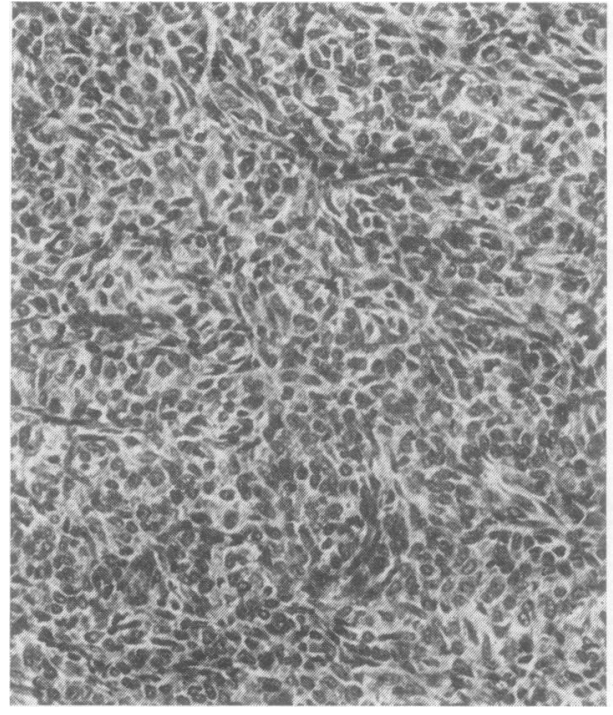

FIG. 4. Histological appearance of the tumour showing tendency to whorl formation. H.E. $\times 200$.

Following myelography, a dorsal laminectomy (Mo. J. W. McIntosh) was carried out at D5, 6, and 7. An encapsulated vascular tumour was found, some $5 \mathrm{~cm}$ $\mathrm{g}$ 을. length, occupying the full width of the spinal canal and lying dorsally and to the right of the cord, which was 8 compressed. The tumour was entirely extradural and $\infty$ extended out through the intervertebral foramen into the thorax. After removal the dura was opened and the cord was seen to pulsate well. Two weeks later, at thoracotomy (Sir Thomas Holmes Sellors), it was possible to carry out a full extrapleural resection of the thoracic portion of the $\frac{0}{\mathbb{D}}$ tumour.

Improvement in the function of his legs was noticeable $\overrightarrow{\vec{P}}$ within 24 hours of spinal cord decompression, and, when $\frac{O}{3}$ he was discharged, a month after admission, abnormalities were confined to exaggerated tendon reflexes in the right leg, a right extensor plantar response, and some distortion of pin appreciation in the legs. Neck flexion $\overline{3}$ was symptomless.

MICROSCOPY Sections were taken from both the spinal and intrathoracic portions of the tumour. The histological $\delta$ features were similar, showing a cellular neoplasm with a $₹$ tendency to whorl formation (Fig. 4), occasional mitotic 0 figures, and many thick-walled blood vessels. Collagen? was present. The appearances were those of a vascular $\frac{D}{9}$ meningioma (Professor W. Blackwood and Dr. W. G. P. Mair).

\section{DISCUSSION}

Although dumb-bell meningiomas occur in relation to the falx, tentorium, and optic foramen (Russell,o Rubinstein, and Lumsden, 1963) and at the cranio- $\Phi$ 
vertebral junction (Cushing and Eisenhardt, reprinted 1962), extension of spinal meningiomas into the thoracic cavity is a surprisingly rare occurrence, which may be a reflection of the very infrequent extradural occurrence of these tumours in the spinal canal. Haft and Shenkin (1963) were able to trace seven wholly extradural meningiomas in their review of 371 cases of extradural spinal neoplasms. Naffziger and Brown (1933) referred to a meningioma in the lower cervical region in continuity with a mass at the apex of the right lung and to another patient in whom the spinal portion of an 'haemangio-endothelioma' at D6 and 7 was removed which was thought to be continuous with a mass in the right thorax.

Local spinal pain is a common occurrence at the site of extramedullary tumours and pain is often referred to the legs with advancing spinal cord compression. The relative vulnerability of motor pathways to compression, with resulting disproportionate motor to sensory loss, is also well known and had attracted William Gull's attention in 1856. The Lhermitte phenomenon (Lhermitte, Bollak, and Nicolas, 1924) which troubled our patient throughout the course of his illness and which was no longer present post-operatively is of some interest occurring, as it did, in relation to a compressive lesion in the dorsal region. The symptom usually points to affection of the dorsal columns in the cervical region but the mechanism is uncertain and extramedullary tumours are among the least common causes.

The plain film radiological appearances in this case were particularly striking and were originally thought to indicate a neurofibroma. Although both Bull (1953) and Gautier-Smith (1967) have drawn attention to the relative frequency of plain film radiological abnormalities in neurofibromas, Bull, in reviewing the radiological findings in 59 spinal meningiomas found changes to be very inconspicuous, consisting of calcification in one case, increase in interpedicular distance in another, and partial destruction of a pedicle in the case of one extradural meningioma. Our findings emphasize that meningiomas, when they occur extradurally, share with neurofibromas in particular, among other benign tumours, the capacity to produce considerable plain film radiological changes, and unless calcifica- tion is present in the meningioma the two tumours may be radiologically indistinguishable.

\section{SUMMARY}

Extradural spinal meningiomas are rare and dumbbell spinal meningiomas exceptionally so, with only two cases previously reported in the literature. This report of a dumb-bell spinal meningioma arising extradurally is therefore of interest and the suggestion is made, after reviewing the radiological features of this and other varieties of benign extramedullary spinal neoplasm, that extensive plain film radiological abnormalities commonly occur with extradural lesions and it is the site of the tumour in relation to the dura that determines the extent of these changes rather than its histological nature.

We are grateful to Dr. Denis Williams, Mr. Valentine Logue, Sir Thomas Holmes Sellors, and the Medical Committee of the National Hospital, Queen Square, for permission to publish this case. We also wish to thank Dr. James Bull for a great deal of helpful advice. The illustrations were prepared in the National Hospital Photographic Department and the photomicrograph by Mr. J. A. Mills.

\section{REFERENCES}

Broager, B. (1953). Spinal neurinoma, a clinical study. Acta psychiat. scand., suppl. 85, 3-241.

Bull, J. W. D. (1953). Spinal meningiomas and neurofibromas. Acta radiol. (Stockh.), 40, 283-300.

Cushing, H. W., and Eisenhardt, L. (Reprinted 1962). In Meningiomas, Pt. 1, p. 171. Hafner, New York.

Gautier-Smith, P. C. (1967). Clinical aspects of neurofibromas. Brain, 90, 359-394.

Gull, W. (1856). Cases of paraplegia. Guy's Hosp. Rep., 3rd series, 2, 143-190.

Haft, H., and Shenkin, H. A. (1963). Spinal epidural meningioma. $J$. Neurosurg., 20, 801-804.

Heuer, G. J. (1929). The so-called hour glass tumours of the spine. Arch. Surg., 18, 935-981.

Lhermitte, J., Bollak, and Nicolas, M. (1924). Les douleurs à type de décharge électrique consécutives à la flexion céphalique dans la sclerose multiple. Rev. neurol., 2, 56-62.

Lombardi, G., and Passerini, A. (1961). Spinal cord tumours. Radiology, 76, 381-391.

Naffziger, H. C., and Brown, H. A. (1933). Hour-glass tumours of the spine. Arch. Neurol. Psychiat. (Chic.), 29, 561-584.

Rasmussen, T. B., Kernohan, J. W., and Adson, A. W. (1940). Pathologic classification, with surgical consideration, of intraspinal tumours. Ann. Surg., LI, 513-530.

Russell, D. S., Rubinstein, L. J., and Lumsden, C. E. (1963). In Pathology of Tumours of the Nervous System, 2nd ed., p. 46. Arnold, London.

Sloof, J. L., Kernohan, J. W., and MacCarty, C. S. (1964). In Primary Intramedullary Tumours of the Spinal Cord and Filum Terminale, p. 14. Saunders, Philadelphia. 